\title{
Influence of Surface Finish and Porosity on the Fatigue behaviour of A356 Aluminium Casting Alloy
}

\author{
Raquel Hidalgo ${ }^{1 *}$, Jon Ander Esnaola ${ }^{1}$, Miren Larrañaga ${ }^{1}$, Iñigo Llavori ${ }^{1}$, Nuria Herrero-Dorca $^{1}$, Iñaki Hurtado ${ }^{1}$, \\ Edurne Otxoa ${ }^{2}$, Patxi Rodríguez ${ }^{2}$, Aitor Kortabarria ${ }^{2}$
}

1 Mondragon University, Loramendi 4, 20500, Arrasate-Mondragón, Guipúzcoa, Spain.

2 Edertek Research Center, Uribarri Auz., 43, 20500 Arrasate-Mondragón, Guipúzcoa, Spain.

\begin{abstract}
In casting parts, due to the manufacturing process, the presence of defects such as porosity, inclusions and oxide films is unavoidable. All these irregularities have a negative effect on the component performance. Several works have demonstrated that, among them, porosity is especially detrimental to the fatigue properties. As most fatigue failures nucleate at the surface of a material, casting defects at or near the surface and surface roughness become an extremely important factor in determining the fatigue strength of cast components. Very little research has been conducted into the influence of both surface quality and porosity on the fatigue behaviour of aluminium castings parts. In the present work, the effects of two different surface qualities (machined and as-cast) on fatigue behaviour of an A356 casting alloy were studied. The S-N curves obtained showed that the cast surface had higher fatigue strength than the machined one. The failure in cast specimens initiated predominantly from valleys of the rough surface near pores or inclusions. On the other hand, in machined surfaces, the cracks initiated directly from surface pores. Thus, the improvement in fatigue life was attributed to a longer crack "initiation" period.
\end{abstract}

\section{Introduction}

Steel components are being replaced with aluminium equivalents due to the need for lighter and more fuel efficient automobiles. Between them, A356 alloy is employed in automotive and aeronautical industry because of its low strength/weight ratio, good castability and treatability. The problem of casting aluminium alloys is the presence of defects, such as inclusions and pores. These defects are detrimental to the fatigue properties(1). On the other hand, surface roughness can also significantly reduce the fatigue strength.

Fatigue cracks are initiated, as a rule, at the surface or subsurface of structural components, and, therefore, fatigue life is sensitive to surface conditions. In some casting components, the highly stressed surface areas where fatigue cracks initiate are machined. Nevertheless, in others, the as-cast surface skin is left intact. Most of the laboratory fatigue tests are performed on specimens with machined surfaces, which do not represent some of the real component surfaces. Thus, the data obtained from test specimens may not reflect the fatigue behaviour of the actual structural components(2). To accurately predict the fatigue life of an actual component, the effects of surface conditions on the fatigue life must be taken into account.

As most fatigue failures nucleate at the surface of a material, casting defects at or near the surface become an extremely important factor in determining the fatigue strength of cast components.

Very little research has been conducted into the influence of both surface quality and porosity on the fatigue behaviour of aluminium castings parts. All authors agree that fatigue strength of specimens with ascast surfaces is lower than that with polished surfaces (2-6). As for the different behaviour of as-cast and machined surfaces on the fatigue behaviour of casting aluminium alloys, the studies are even fewer. S. Jiang (3) showed that specimens with as-cast surfaces presented higher fatigue strength than those with machined surfaces. Nevertheless, this may be questionable because the microstructural aspects were not constant for all the specimens.

Therefore, in the present work, the effects of two different surface qualities (machined and as-cast) on fatigue behaviour of an A356 casting alloy were studied. All specimens were cast in permanent a mould under the same conditions to avoid the influence of microstructural variables (SDAS, grain size, composition...). Then, some of them were machined before testing.

\footnotetext{
Corresponding author: rhidalgo@mondragon.edu
} 
The S-N curves for each condition were obtained and the fatigue cracks initiation sites were identified using Scanning Electron Microscope (SEM).

\section{Experimental procedure}

Samples were obtained from A356 alloy ingots (A1-7Si$0.3 \mathrm{Mg}$ ). The molten alloy was poured into a preheating permanent mould from which two dog bone specimens were obtained each time. Next, all cast specimens were heat treated in the T6 condition: solution treatment at $540^{\circ} \mathrm{C}$ for 6 hours followed by a warm-water quench and age hardening at $160^{\circ} \mathrm{C}$ for 5 hours.

The dimensions of the cast samples were: total length $190 \mathrm{~mm}$, diameter of the grip parts $19 \mathrm{~mm}$, gauge length and diameter of 50 and $12 \mathrm{~mm}$, respectively. As two different surface conditions were needed, some samples were machined to a final diameter of $11 \mathrm{~mm}$. The dimensions of the samples can be seen in Fig. 1



(a)

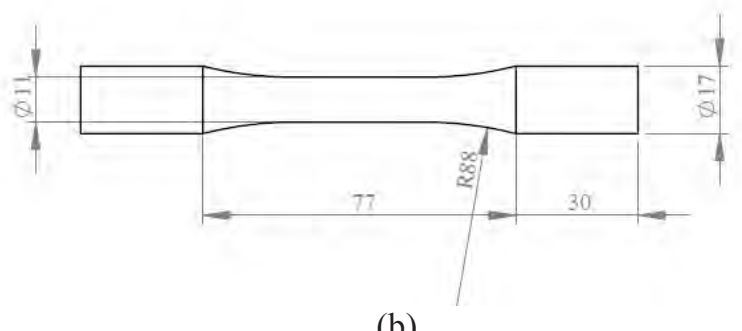

Fig. 1. Fatigue test samples (dimensions in mm) a) Cast sample b) Machined sample.

The roughness of the samples was measured with a Mitutoyo Portable Surface Roughness Tester. To measure the shape and analyse the surface, an Alicona InfiniteFocusSL was employed.

The high-cycle fatigue tests were conducted according to the ASTM-E466 test procedure specifications with sinusoidal loading using an MTS810 Materials Testing System at room temperature. The fatigue test was performed using a stress ratio of $\mathrm{R}=-1$ with a frequency of $10 \mathrm{~Hz}$.

The fatigue strength coefficient and exponent in Basquin's equation were obtained via regression analysis of the experimental data using the least-squares method.

To identify the places where the fatigue cracks initiated for each condition, a scanning electron microscope FEI Nova Nano SEM 450 was used.

\section{Results and Discussion}

\subsection{Surface roughness}

The surface roughness was measured on as-cast and machined surfaces with a Mitutoyo Portable Surface Roughness Tester. Two parameters were studied: the Ra and Rz. The $\mathrm{Ra}$ is a widely used parameter for assessment of surface roughness, its value reflects the average length between the peaks and valleys of the profile. However, for fatigue analysis. The Rz parameter, which corresponds to the maximum peak-to-valley height, is a more suitable measure. Fig. 2 compares these parameters for both samples, each value being the average of three measurements.

What stands out in the graph is the significant difference in $\mathrm{Ra}$ and $\mathrm{Rz}$ parameters. Based on these results it can be concluded that cast specimens presented greater roughness than machined ones.

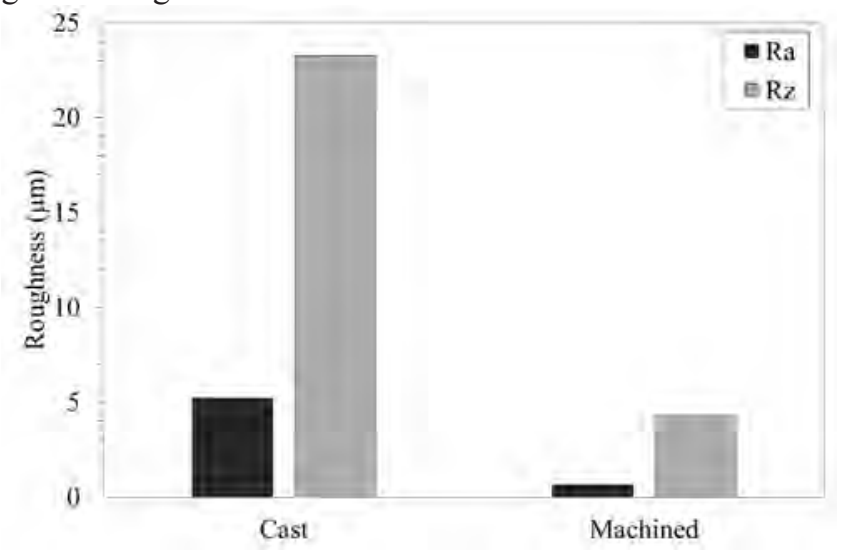

Fig. 2. Surface Roughness ( $R a$ and $R z)$ of as-cast and machined samples.

The considerable difference between the two surfaces are also clearly seen in the 3D image in Fig. 3 obtained with Alicona InfiniteFocusSL.

The as-cast surface was very irregular as a result of deep hollows and steep peaks which came from the paint used in the mould. On the other hand, the machined surface was smoother presenting only superficial machined grooves.

Similarly, Fig. 4 compares the topographic profile of the two samples. The maximum peak-to-valley height was around $30 \mu \mathrm{m}$ for the cast sample and $5 \mu \mathrm{m}$ for the machined one. This supported the results measured in Fig. 2.

The big difference of parameters in Fig. 2 is clearly explained by the two different surfaces observed in Fig. 3 and the profiles in Fig. 4. 


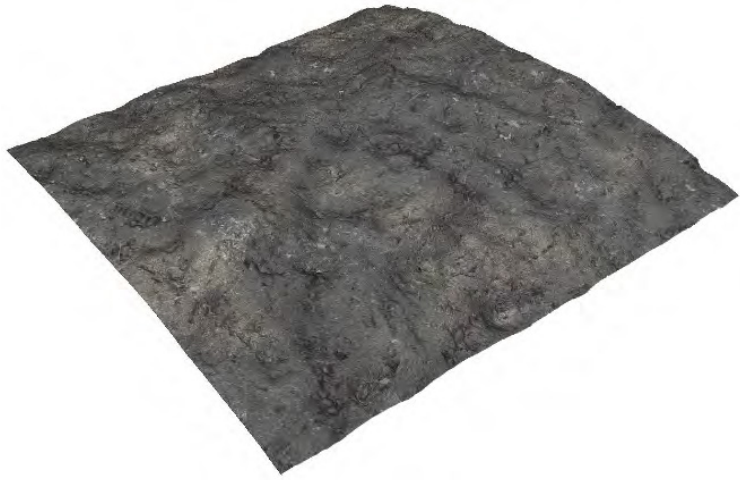

(a)

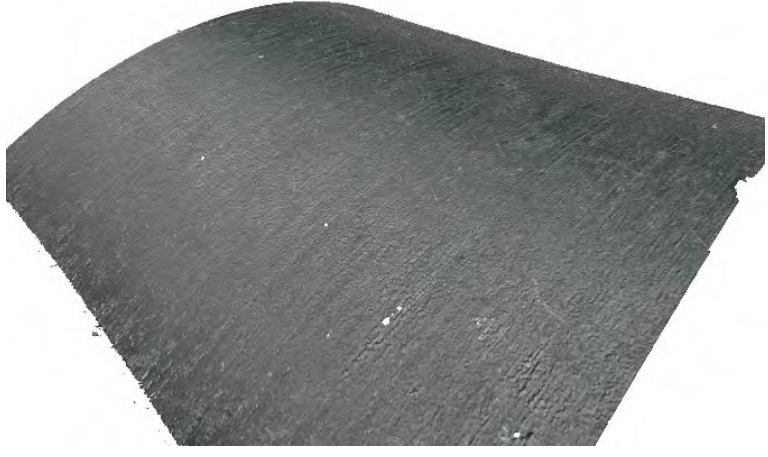

(b)

Fig. 3. Image showing the 3D surface roughness of a) as-cast and b) machined samples.

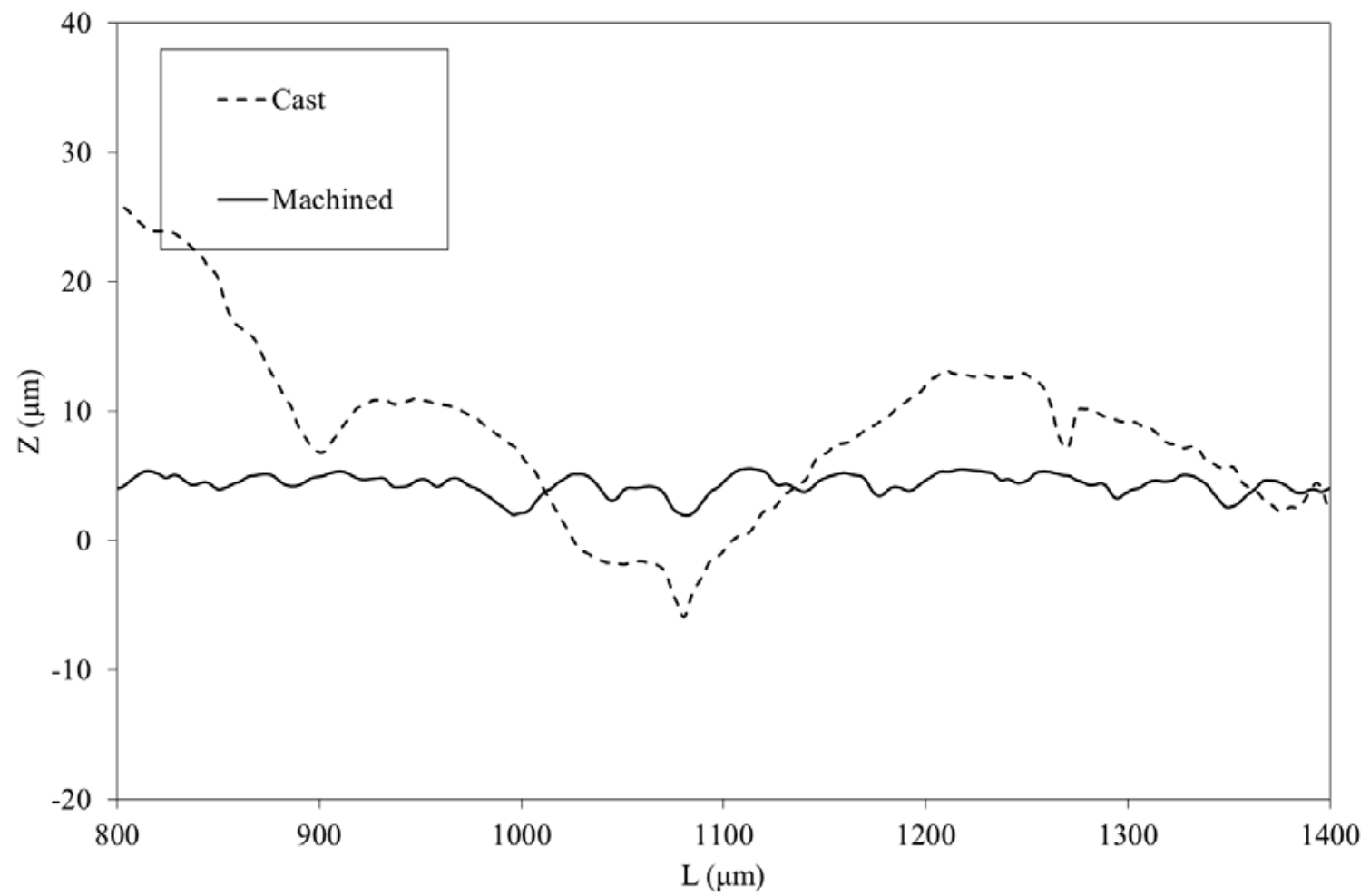

Fig. 4. Topographic profile of the samples.

\subsection{Porosity}

The microstructure of A356 alloy consisted of Al dendrites surrounded by eutectic silicon phase.

There were two types of porosity found in the samples as shown in Fig. 5. Shrinkage pores were the predominant porosity found in the samples. This kind of porosity results from insufficient metal flow into the space between connected dendrites during the solidification process. Only a few defects were gas pores. The shrinkage pores had very irregular threedimensional shapes and varied sizes, whereas the gas pores were usually roughly spherical (circular in crosssection). Typical examples of a shrinkage pore and a gas pore are shown in Fig. 5

\subsection{Fatigue Tests}

To compare the difference between the fatigue behaviour of cast and machined specimens, fatigue tests were carried out in samples with both surface conditions. Fig. 6 shows S-N curves obtained where the number of cycles to failure $\left(\mathrm{N}_{\mathrm{f}}\right)$ is plotted against stress amplitude applied $\left(\mathrm{S}_{\mathrm{a}}\right)$. As can be seen in the graph, for a given stress amplitude, the machined surface present a higher fatigue life than the cast one.

Previous investigations indicated that almost all fatigue fractures start from the sites of stress concentrations at structural discontinuities such as holes, notches, grooves, cracks, defects, and scratches(3). Thus, to understand the difference in the fatigue behaviour among the two types of surface conditions, the places where the fatigue failure starts must be studied. 


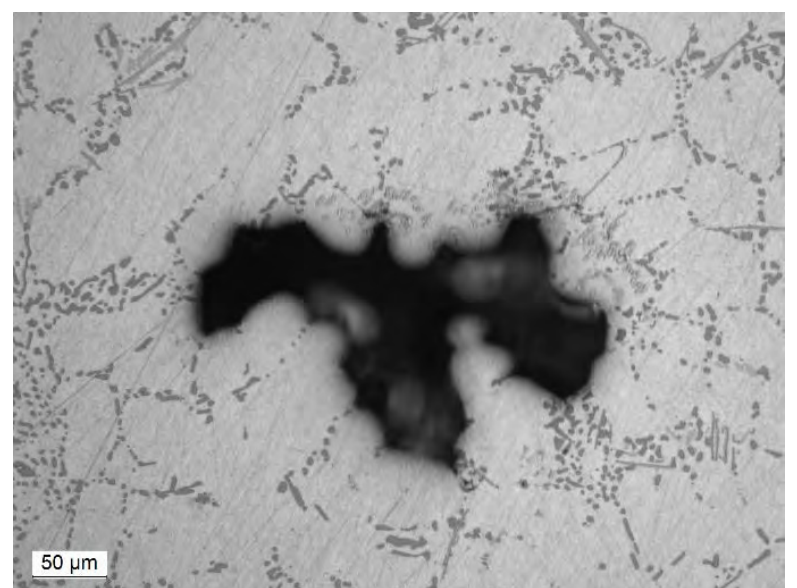

(a)

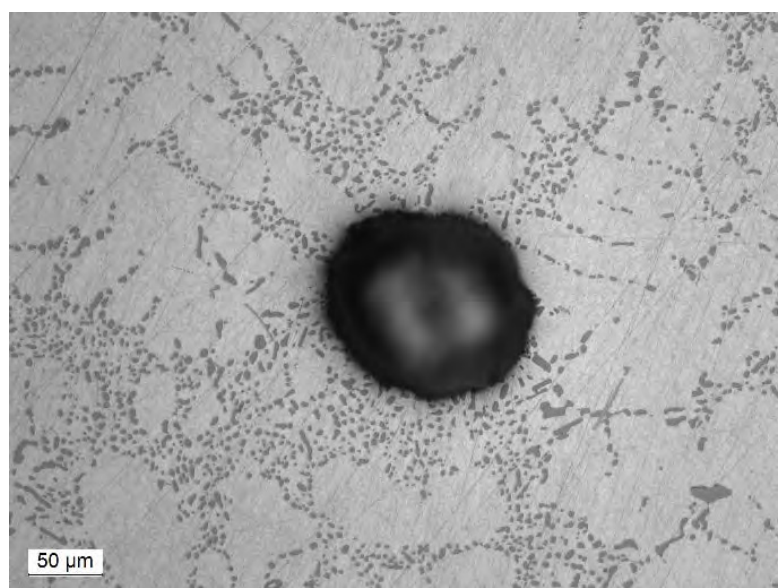

(b)

Fig. 5. Optical micrographs of (a) a shrinkage pore.(b) a gas pore.

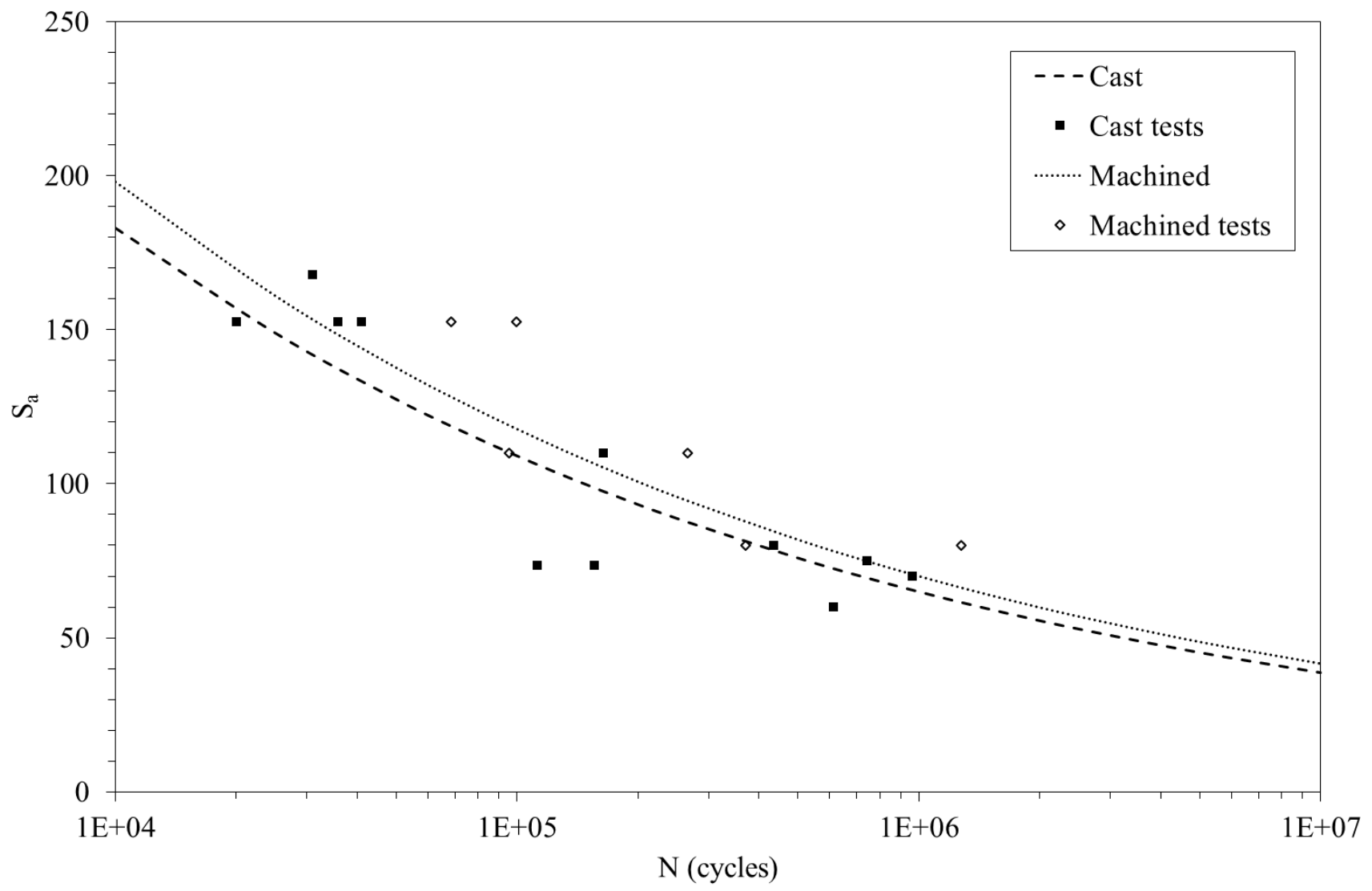

Fig. 6. Fatigue life curves for cast and machined samples.

SEM was used to carry out the fractographic study. For cast specimens, failure initiated predominantly from valleys of the rough surface near pores or inclusions as shown in Fig. 7. On the other hand, in machined surfaces, the cracks were initiated directly from surface pores.

Taking into account that all the samples were cast under the same conditions, no microstructure variations existed and the average porosity can be considered constant in all the samples. For this reason, the only difference was the roughness. The fatigue results in Fig. 6 can be related to roughness in Fig. 2, Fig. 3 and Fig. 4. It can be concluded that a decrease in surface roughness in the machined materials increased the difficulty of crack initiation and, hence, increased the fatigue life. Therefore, in this case, the improvement in fatigue life was attributed to a longer crack "initiation" period. This explained the results in Fig. 6 and it correlated well with previous studies $(2,5)$

However, this outcome is contrary to that of Jiang S. et al. (3) who found that grooves on specimens with machined surface roughness of $\mathrm{Ra}=1.6$ and $3.2 \mu \mathrm{m}$ were deep and sharp, which reduced the fatigue strength considerably compared with as-cast specimens. In this study, the grooves were not deep and sharp as shown in

\footnotetext{
Corresponding author: rhidalgo@mondragon.edu
} 
Fig. 4 which could explain the different results obtained.

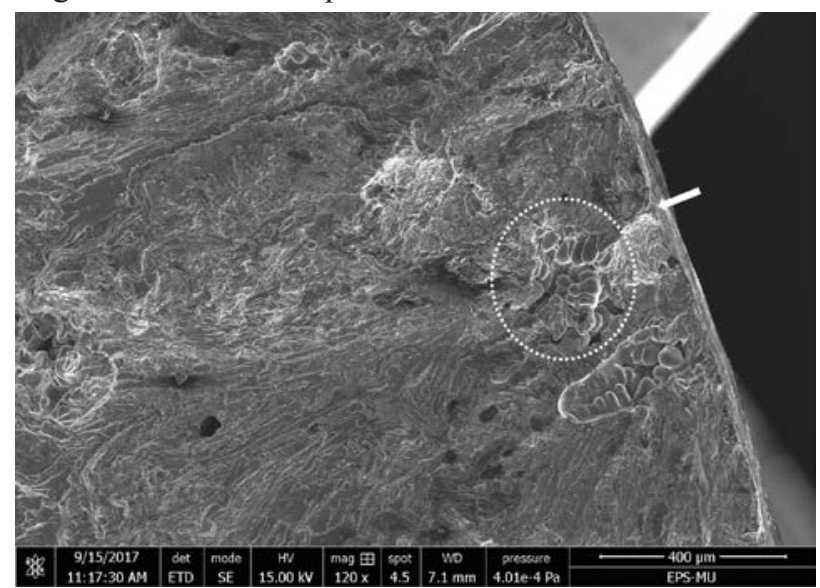

(a)

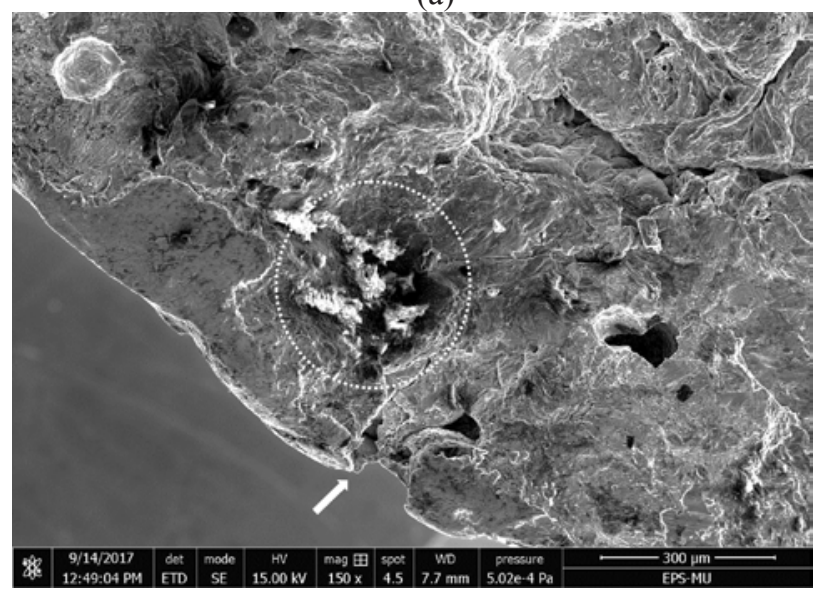

(b)

Fig. 7. Fatigue fracture surface of a cast specimen showing initiation from a valley near (a) a shrinkage pore (b) an inclusion.

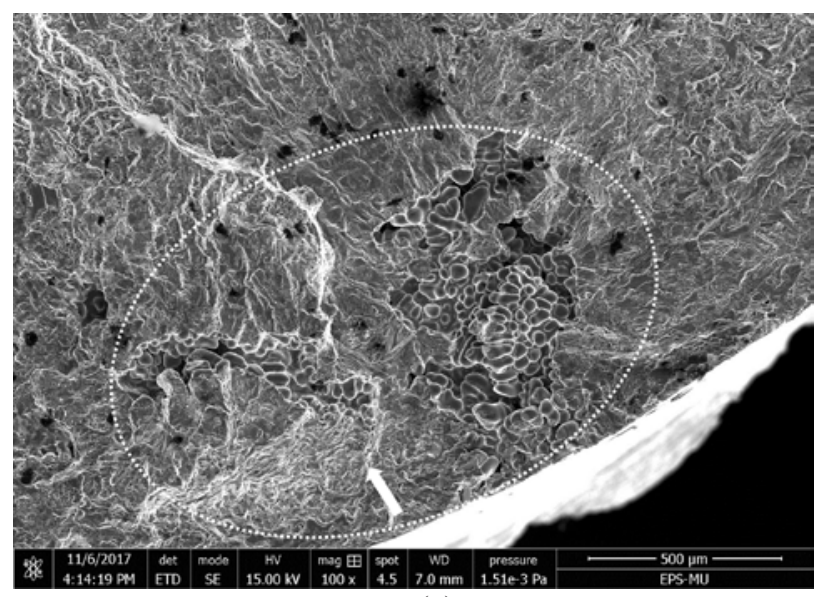

(a)

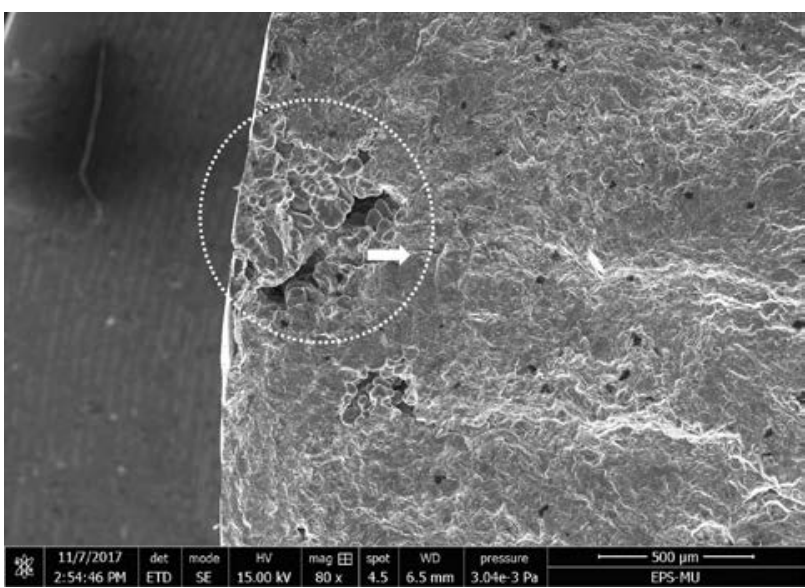

(b)

Fig. 8. Fatigue fracture surface of machined samples showing crack initiation from surfaces pores.

\section{Conclusions}

The aim of this investigation was to study the difference in the fatigue behaviour of A356 alloys considering two different surface conditions; machined and cast.

- The measurements of roughness parameters, the 3D images and the topographic profiles indicated that the as-cast specimens had greater surface roughness than machined ones.

- The S-N curve showed that fatigue life fatigue life of machined specimens was higher than that of cast ones.

- The cracks in as-cast samples initiated from valleys of the rough surfaces near pores or inclusions. In the machined samples, the surface roughness was reduced and the failure was observed to start in pores near the surface.

- A decrease in the roughness of machined samples changed the mechanisms of crack initiation which explained the results of fatigue life curves:

The authors acknowledge the financial support provided by the Ministry of Industry Economics and Competitiveness of the Spanish Government by means of ALPRE project (RTC-20153822-4) and the FEDER funds from the European Union.

\section{References}

1. Linder J, Axelsson M, Nilsson H. The influence of porosity on the fatigue life for sand and permanent mould cast aluminium. 2006;

2. Jiang $\mathrm{H}$, Bowen $\mathrm{P}$, Knott JF. Fatigue performance of a cast aluminium alloy Al-7Si$\mathrm{Mg}$ with surface defects. J Mater Sci. 1999;34(4):719-25.

3. Jiang $\mathrm{SN}, \mathrm{Xu} \mathrm{SY}$. Influence of Surface Conditions on the Fatigue Behavior of A357 Aluminum Alloy. Mater Sci Forum [Internet]. 
2016;850:113-9. Available from: http://www.scientific.net/MSF.850.113

4. Serrano-Munoz I, Buffiere J-Y, Verdu C, Gaillard Y, Mu P, Nadot Y. Influence of surface and internal casting defects on the fatigue behaviour of A357-T6 cast aluminium alloy. Int J Fatigue. 2016;

5. Yamabe J, Kobashi M. Influence of casting surfaces on fatigue strength of ductile cast iron. Fatigue Fract Eng Mater Struct. 2006;29(6):40315.

6. Svenningsson R, Svensson H, Borgström H, Gotte A. Influence of the surface roughness on the fatigue properties in ausferritic ductile irons (ADI). MATEC Web Conf [Internet]. 2014;12:6006. Available from: http://www.scopus.com/inward/record.url?eid=2 -s2.0-84903288711\&partnerID=tZOtx3y1 